\title{
Dietary trans fatty acids increase serum cholesterylester transfer protein activity in man
}

\author{
Arie van Tol*a, Peter L. Zock ${ }^{\mathrm{b}}$, Teus van Gent ${ }^{\mathrm{a}}$, Leo M. Scheek ${ }^{\mathrm{a}}$, Martijn B. Katan ${ }^{\mathrm{b}}$ \\ ${ }^{a}$ Department of Biochemistry, Cardiovascular Research Institute (COEUR), Faculty of Medicine and Health Sciences, \\ Erasmus University, P.O. Box 1738, 3000 DR Rotterdam, The Netherlands \\ ${ }^{b}$ Department of Human Nutrition, Agricultural University, Wageningen, The Netherlands
}

Received 8 November 1994; revision received 21 December 1994; accepted 22 December 1994

\begin{abstract}
The average diet may provide some $8-10 \mathrm{~g} /$ day of unsaturated fatty acids with a trans double bond. Previous studies showed that dietary trans fatty acids may simultaneously raise low-density lipoprotein (LDL) cholesterol and reduce high-density lipoprotein (HDL) cholesterol. Human plasma contains a protein (CETP) which transfers cholesterylesters from HDL to lipoproteins of lower density. We hypothesized that CETP could play a role in the effect of trans fatty acids on lipoproteins and measured the activity levels of CETP in serum samples from a 9-week study in which 55 volunteers were fed three controlled diets with different fatty acid profiles. Mean activity was 114 (\% of reference serum) after consumption of a high trans fatty acid diet, as opposed to 96 after linoleic acid and 97 after stearic acid $(P<0.02)$. We conclude that the increased activity of CETP may contribute to the rise in LDL cholesterol and the fall in HDL cholesterol seen on diets with high contents of trans fatty acids.
\end{abstract}

Keywords: Atherosclerosis; Coronary heart disease; Dietary trans fatty acids; Cholesterylester transfer protein (CETP); High-density lipoproteins (HDL); Lecithin:cholesterol acyltransferase (LCAT); Low-density lipoproteins (LDL)

\section{Introduction}

Commercial hardening of vegetable oils leads to the formation of unsaturated fatty acids with

Abbreviations: Apo, apolipoprotein; CETP, cholesterylester transfer protein; HDL, high-density lipoproteins; LCAT, lecithin:cholesterol acyl-transferase; LDL, low-density lipoproteins; VLDL, very-low-density lipoproteins.

* Corresponding author, Tel.: $31 \quad 10$ 4087321; Fax: 3110 4360615 . double bonds in the trans instead of the natural cis configuration. The same process takes place in the rumen of cows and sheep and trans fatty acids produced here end up in the milk and meat of these species. As a result the average daily US diet contains 8-10 grams of trans unsaturated fatty acids [1].

Dietary trans fatty acids may simultaneously raise low-density lipoprotein (LDL) cholesterol and reduce high-density lipoprotein (HDL) 
cholesterol levels [2-4], or at least elevate LDL cholesterol/HDL cholesterol $[5,6]$. These changes represent a more atherogenic lipoprotein profile, which could explain the association of trans fatty acid intake and coronary heart disease reported in women [7].

Animal species that lack cholesterylester transfer protein (CETP) activity in plasma (e.g. the rat) have low LDL and relatively high plasma HDL cholesterol concentrations and tend to be resistant to atherosclerosis. Susceptibility to atherogenic diets is high in species with high plasma CETP activity like rabbits and man [8]. CETP catalyzes the transfer of plasma cholesterylesters, synthesized by lecithin:cholesterol acyltransferase (LCAT), from HDL to the apolipoprotein (apo) B-containing lipoproteins LDL and very low-density lipoproteins (VLDL) [9]. The HDL cholesterol concentration is elevated in plasma of individuals with familial CETP deficiency, and some of these families appear to experience longevity [10]. Intravenous injection of purified human CETP into rats results in a decrease in HDL cholesterol and in a doubling of plasma apo $B$ levels [11]. Also, the expression of human CETP in transgenic mice leads to a substantial decrease in HDL cholesterol, especially when the mice also express the human apo A-I gene [12]. Information on the regulation of plasma CETP activity is incomplete. The present knowledge on this subject has been reviewed recently [13].

We hypothesized that plasma CETP activity could play a role in the induction of low HDL and high LDL cholesterol levels by dietary trans fatty acids in man. We therefore measured the serum activity levels of CETP (using excess exogenous substrate assays) in sera from a diet study involving the comparison of linoleic acid, stearic acid and trans fatty acids under carefully controlled conditions [3].

\section{Methods}

\subsection{Design and statistical analysis}

The hypothesis that CETP was involved in the lowering of HDL and increase in LDL seen after the consumption of dietary trans fatty acids arose after the lipoprotein data had been published
$[2,3]$. The present data were obtained using spare sera stored at $-80^{\circ} \mathrm{C}$ from the study described [3]. For details of the diet study (subjects, protocol, diet composition and effects on serum lipids and lipoproteins), refer to the original reference [3]. In short, the trial consisted of three consecutive 3-week periods, during which each participant consumed each of three diets, rich in either trans fatty acid, stearic acid or linoleic acid. Each of the six possible diet sequence groups had a nearly equal number of male and female subjects, and of women using and not using oral contraceptives. In this way, bias due to order in which the diets are consumed, drift of variables over time, or to effects of hormonal cycle was eliminated.

The data were analyzed applying a within-subjects model of the Statistical Analysis System (SAS Institute). When the analysis of variance indicated a significant effect of diet $(P<0.05)$, the Tukey method was used for pairwise comparisons of the diets and for calculation of $95 \%$ confidence intervals. Only $P$-values $<0.02$ were considered significant after this adjustment for multiple comparisons.

Fifty-six healthy, normolipidemic volunteers completed the original trial [3], but for the present analysis one serum sample was missing of one man on the high-elaidic acid diet. All present analyses are therefore based on 30 women and 25 men, in whom CETP and LCAT were determined after 17 days on each of the three diets.

\subsection{Diets}

The composition of the three diets was similar [3], except for about $8 \%$ of daily energy, which was supplied by either linoleic, stearic or trans fatty acids. The diets consisted of conventional solid foods and menus were changed daily during each 3-week cycle. All foodstuffs were supplied individually according to each person's energy requirement. Body weights were essentially constant during the 9 weeks of the study.

\subsection{LCAT and CETP assays}

CETP activity was assayed in the supernatant fraction of each serum after removal of endogenous VLDL + LDL by phosphotungstate $/ \mathrm{Mg}^{2+}$ precipitation [14]. The assay detects the transfer/ 
exchange of cholesterylesters between excess exogenous $\left[{ }^{14} \mathrm{C}\right]$ cholesterylester-labelled LDL and excess exogenous unlabelled normal HDL, while LCAT is inhibited with $2 \mathrm{mmol} / \mathrm{l}$ of 2-nitro-benzoic acid [15]. Exogenous HDL-cholesterylesters (200 nmoles) are added to the assay system providing a 10-15-fold excess over the endogenous HDL-cholesterylesters present. It was shown before that the assay measures identical activities with added HDL-cholesterylesters in the range of $150-300$ nmoles. It is therefore highly unlikely that small changes in the composition of endogenous HDL (e.g. the changes in the cholesterylester/triglyceride ratio as shown in the present paper) will affect the results. Incubations were for $16 \mathrm{~h}$ at $37^{\circ} \mathrm{C}$. The reaction was stopped by cooling the tubes to $4^{\circ} \mathrm{C}$ and $\mathrm{LDL}$ was precipitated from the incubation mixture with $\mathrm{Mg}$-phosphotungstate [16] and the radioactivity was measured in the HDL-containing supernatant. CETP activity was calculated as the bidirectional transfer of cholesterylesters between radiolabelled LDL and HDL [15].

Serum LCAT activity levels were determined using excess exogenous substrate containing $\left[{ }^{3} \mathrm{H}\right]$ cholesterol [17]. Samples were incubated for $6 \mathrm{~h}$ at $37^{\circ} \mathrm{C}$ in a total volume of $0.145 \mathrm{ml}$ before the reaction was stopped by addition of $0.30 \mathrm{ml}$ cold methanol and the lipids were extracted twice with $0.4 \mathrm{ml}$ hexane. Free and esterified cholesterol were separated using disposable silica columns. $\left[{ }^{3} \mathbf{H}\right]-$ cholesterylesters were eluted with $3.0 \mathrm{ml}$ hexane:diethylether $(6: 1, \mathrm{v} / \mathrm{v})$.

LCAT and CETP activity assays were performed in duplicate. The measured activities were linear with the amount of serum used. The withinassay coefficients of variation are $4.5 \%$ and $2.7 \%$, respectively. The measured activities reflect the activity of LCAT or CETP as such, and are independent of the endogenous lipoproteins present in each serum. The activities were expressed in arbitrary units, relative to the activities in a human pool serum that was included in each run (\% reference serum). LCAT and CETP activities are stable during storage of serum at $-80^{\circ} \mathrm{C}$. The pooled human serum, used as a reference serum included in each assay run, was prepared in 1988 and kept at this temperature. A second reference serum (pooled human serum prepared in 1994) had identical CETP and LCAT activity levels if compared in the same assay run, indicating the stability of the activities over a 5-6 year period in samples stored at $-80^{\circ} \mathrm{C}$. Of course small intrinsic differences between the activities in the 1988 and 1994 reference sera may exist and therefore minor changes during storage cannot be excluded completely. The absolute activities in the 1988 pool serum were 181.9 and $39.2 \mathrm{nmoles} / \mathrm{ml} / \mathrm{h}$ for CETP and LCAT, respectively.

\section{Results}

CETP and LCAT activities are shown in Table 1. LCAT activities were not significantly different between the diet groups and the same activity levels were measured in males and females. In contrast, CETP activity was specifically elevated on the trans-diet compared with the other two diets. The CETP activities measured after the stearate-diet and the linoleate-diet were identical, despite the higher VLDL + LDL cholesterol after the stearate-diet [3]. The trans-diet was accompanied by an $18 \%$ increase in CETP activity if all subjects were analysed together. CETP activity levels in females and males were not significantly different on any diet. The increase in CETP activ-

Table 1

Mean activity of LCAT and CETP on the three study diets

\begin{tabular}{llll}
\hline & $\begin{array}{l}\text { Linoleate } \\
\text { diet }\end{array}$ & $\begin{array}{l}\text { Stearate } \\
\text { diet }\end{array}$ & $\begin{array}{l}\text { Elaidate } \\
\text { diet }\end{array}$ \\
\hline LCAT & & & \\
$\quad$ Men & $84.1 \pm 19.0$ & $90.8 \pm 18.1$ & $84.3 \pm 18.9$ \\
Women & $86.2 \pm 16.2$ & $87.4 \pm 18.8$ & $85.2 \pm 15.2$ \\
All & $85.2 \pm 17.4$ & $88.9 \pm 18.4$ & $84.8 \pm 16.8$ \\
CETP & & & \\
Men & $97.5 \pm 19.9$ & $98.1 \pm 20.6$ & $117.7 \pm 24.9^{\mathrm{b}, \mathrm{c}}$ \\
Women & $95.2 \pm 21.4$ & $96.6 \pm 19.6$ & $111.5 \pm 21.5^{\mathrm{b}, \mathrm{c}}$ \\
All & $96.2 \pm 20.5$ & $97.3 \pm 19.9$ & $114.3 \pm 23.1^{\mathrm{b}, \mathrm{c}}$ \\
\hline
\end{tabular}

${ }^{a}$ The 25 men and 30 women consumed each diet for three weeks, in random order. Activities were determined in fasting serum samples obtained after 17 days on each diet, expressed as $\%$ of the activity in a reference serum \pm S.D.

${ }^{\mathrm{b}}$ Significantly different from high-linoleate diet; $P<0.02$.

${ }^{\mathrm{c}}$ Significantly different from high-stearate diet; $P<0.02$. 


\section{$\triangle$ CETP activity $(\%)$}
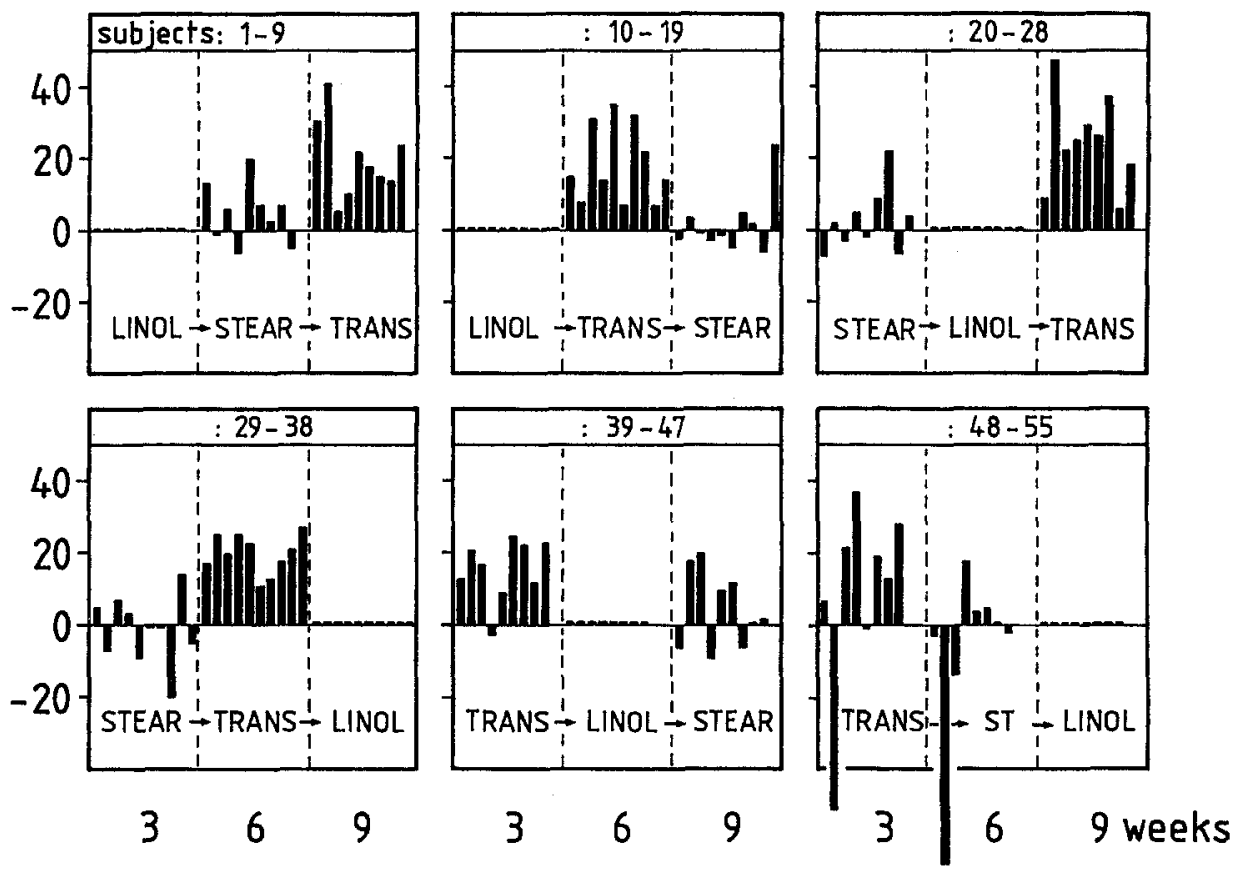

Fig. 1. Individual changes in CETP activity on diets high in trans fatty acids or stearic acid, relative to a diet high in linoleic acid. Bars indicate the CETP activity of each individual subject when on a particular diet minus his or her activity when on the linoleic acid diet.

ity after the trans-diet was seen in 52 out of 55 individuals; one individual showed no effect and two showed a decrease in activity. Fig. 1 illustrates these individual changes on the trans-diet or stearate-diet, relative to the linoleate-diet.

The increased CETP activity on the trans-diet coincided with a low cholesterylesters/triglycerides in HDL. The average molar ratio ( \pm S.D.) was $6.15 \pm 1.83$ on the trans -diet vs. $6.97 \pm 2.19$ on the linoleate-diet and $6.71 \pm 2.25$ on the stearate$\operatorname{diet}(P<0.02)$.

\section{Discussion}

We observed a specific elevation in serum CETP activity in subjects fed diets enriched in trans fatty acids: by $21 \%$ in males and by $17 \%$ in females. LCAT activity levels were not significantly different on the three diets. Compared with the linoleate-diet, only the trans-diet increased
CETP activity, even though both the stearate-diet and the trans-diet resulted in an increase in LDL cholesterol, and in the VLDL + LDL cholesterol/ HDL cholesterol ratio and total serum cholesterol/HDL cholesterol ratio [3]. Thus the effects on VLDL + LDL cholesterol levels and on CETP activity are not obligatory coupled. This is not surprising because, in addition to possible effects of CETP, VLDL and LDL synthesis and degradation are major contributors to plasma VLDL + LDL cholesterol levels. At the individual level, changes in CETP activity between diets were only weakly associated with changes in lipoprotein composition and concentration. The strongest correlation observed $(r=0.35$, $P=0.008$ ) was between the changes in CETP activity and apolipoprotein $B$ concentration on the trans-diet versus the stearate-diet. However, random noise in both the lipoprotein and CETP measurements will attenuate such individual asso- 
ciations and very large groups of subjects are required to allow the signal to rise above the noise.

It was reported that high concentrations of elaidic acid, added in vitro, may increase the transfer of cholesterylesters from HDL to LDL [18]. Therefore, trans fatty acids could act by increasing the serum levels of CETP, as suggested by our data, or by increasing the efficiency of the transfer process, as found in the in vitro experiments. Recently, Abbey and Nestel [19] reported increased CETP activity after substitution of trans-elaidic acid for $c i s$-oleic acid in the diet. A significant increase was only detected using a CETP activity assay employing endogenous lipoproteins, but absent if CETP activity was assayed in lipoprotein-deficient plasma. The CETP activity assay used in the present experiments is independent of endogenous lipoproteins [15] and correlates very well with CETP mass [20]. So dietary trans fatty acids may increase the transfer of cholesterylesters by increasing CETP mass as well as by changing the structure of plasma lipoproteins, resulting in better substrates for CETP action. Alternatively, trans fatty acids could decrease the activity of putative CETP inhibitors [21].

Analysis of the lipid composition in HDL revealed the lowest cholesterylester/triglyceride ratio on the diet high in trans fatty acids. This may indicate that the high plasma CETP activity found on this diet indeed affects the lipid transfer reactions between lipoproteins (exchange of cholesterylesters in HDL for triglycerides in VLDL) occurring in vivo. It cannot be excluded however that other actions of dietary trans fatty acids affecting $\mathrm{HDL}$ (e.g. effects on $\mathrm{HDL}_{2} / \mathrm{HDL}_{3}$ via LCAT action, lipoprotein lipase and hepatic lipase) also explain the changes in chemical composition of HDL. It was shown before that the fatty acid profile of serum cholesterylesters was influenced significantly by the various diets confirming the subjects' adherence to the diets [3]. The trans-diet resulted in a several fold increase in cholesterylesters with trans $\mathrm{C} 18: 1$ fatty acid, but even on this diet only about $1 \%$ of serum cholesterol was esterified with trans $\mathrm{C} 18: 1$ fatty acid (compared with $0-0.3 \%$ on the stearate-diet). This was the only significant difference in cholesterylester fatty acid profile between these two diets [3]. It is highly unlikely that these small changes in cholesterylester fatty acid profile contribute to the observed differences in CETP activity, using an assay method which is not influenced by the concentration of endogenous lipoproteins.

Recent data indicate an effect of exercise on plasma CETP activity [22,23], but our study subjects (aged 19-49 years) did not change their excercise habits during the course of the experiment [3]. As in a previous study [16], we were unable to detect significant differences in CETP activity between males and females. This is in line with published data on CETP mass in elderly, sedentary subjects [22], as well as CETP activity (measured with exogenous substrates) in marathon runners aged 25-51 years [23].

Diminished levels of plasma CETP activity are often associated with a low-risk lipoprotein profile [8-11], while increased CETP levels are found in patients with various forms of hyperlipidemia [24]. Also, intravenous injection of CETP into rats [11], or introduction of CETP into mice by transgenesis [12] results in a rise in LDL and a fall in HDL cholesterol. These changes are similar as seen in humans consuming high trans fatty acid diets [2-4]. Experiments with mice [25] and monkeys [26] fed atherogenic diets, revealed close correlations between atherosclerosis development, LDL cholesterol concentrations and plasma CETP levels. Our present data support the notion that the increased CETP activity induced by dietary trans fatty acids may contribute to unfavorable lipoprotein profiles and atherogenesis.

\section{References}

[1] Hunter JE, Applewhite TH. Reassessment of trans fatty acid availability in the US diet. Am $J$ Clin Nutr 1991;54:363.

[2] Mensink RPM, Katan MB. Effect of dietary trans fatty acids on high-density and low-density lipoprotein cholesterol levels in healthy subjects. $\mathrm{N}$ Engl $\mathrm{J}$ Med 1990;323:439.

[3] Zock PL, Katan MB. Hydrogenation alternatives: effects of trans fatty acids and stearic acid versus linoleic acid on serum lipids and lipoproteins in humans. J Lipid Res 1992;33:399. 
[4] Judd JT, Clevidence BA, Muesing RA, Wittes J, Sunkin ME, Podczasy JJ. Dietary trans fatty acids: effects on plasma lipids and lipoproteins of healthy men and women. Am J Clin Nutr 1994;59:861.

[5] Nestel P, Moakes M, Belling B, McArthur R, Clifton P, Janus E, Abbey M. Plasma lipoprotein lipid and Lp(a) changes with substitution of elaidic acid for oleic acid in the diet. J Lipid Res 1992;33:1029.

[6] Lichtenstein AH, Ausman LM, Carrasco W, Jenner JL, Ordovas JM, Schaefer EJ. Hydrogenation impairs the hypolipidemic effect of corn oil in humans. Hydrogenation, trans fatty acids, and plasma lipids. Arterioscler Thromb 1993;13:154.

[7] Willett WC, Stampfer MJ, Manson JE, Colditz GA, Speizer FE, Rosner BA, Sampson LA, Hennekens CH. Intake of trans fatty acids and risk of coronary heart disease among women. Lancet 1993;341:581.

[8] Ha YC, Barter PJ. Differences in plasma cholesteryl ester transfer activity in sixteen vertebrate species. Comp Biochem Physiol 1982;71B:265.

[9] Eisenberg S. High density lipoprotein metabolism. J Lipid Res 1984;25:1017.

[10] Inazu A, Brown ML, Hesler CB, Agellon LB, Koizumi J, Takata K, Maruhama Y, Mabuchi H, Tall AR. Increased high density lipoprotein caused by a common cholesteryl ester transfer protein gene mutation. $\mathrm{N}$ Engl J Med 1990;323:1234.

[11] Groener JEM, Van Gent T, Van Tol A. Effect of lipid transfer protein on plasma lipids, apolipoproteins and metabolism of high-density lipoprotein cholesteryl ester in the rat. Biochim Biophys Acta 1989;1002:93.

[12] Hayek T, Chajek-Shaul T, Walsh A, Agellon LB, Moulin P, Tall AR, Breslow JL. An interaction between the human cholesteryl ester transfer protein (CETP) and apolipoprotein A-I genes in transgenic mice results in a profound CETP-mediated depression of HDL cholesterol levels. J Clin Invest 1992;90:505.

[13] Tall AR. Plasma cholesteryl ester transfer protein. J Lipid Res 1993;34:1255.

[14] Speijer H, Groener JEM, Van Ramshorst, E, Van Tol A. Different locations of cholesterylester transfer protein and phospholipid transfer protein activities in plasma. Atherosclerosis 1991;90:159.
[15] Groener JEM, Pelton RW, Kostner GM. Improved estimation of cholesteryl ester transfer/exchange activity in serum or plasma. Clin Chem 1986;32:283.

[16] Groener JEM, Van Ramshorst EM, Katan MB, Mensink RP, Van Tol A. Diet-induced alteration in the activity of plasma lipid transfer protein in normolipidemic human subjects. Atherosclerosis 1991;87:221.

[17] Glomset JA, Wright JL. Some properties of a cholesterol esterifying enzyme in human plasma. Biochim Biophys Acta 1964;89:266.

[18] Lagrost L. Differential effects of cis and transfatty acid isomers, oleic and elaidic acids, on cholesteryl ester transfer protein activity. Biochim Biophys Acta 1992;1124:159.

[19] Abbey M, Nestel PJ. Plasma cholesteryl ester transfer protein activity is increased when trans-elaidic acid is substituted for cis-oleic acid in the diet. Atherosclerosis 1994;106:99.

[20] Hannuksela M, Marcel YL, Kesäniemi YA, Savolainen MJ. Reduction in the concentration and activity of plasma cholesterylester transfer protein by alcohol. J Lipid Res 1992;33:737.

[21] Son YSC, Zilversmit DB. Purification and characterization of human plasma proteins that inhibit lipid transfer activities. Biochim Biophys Acta 1994;795:473.

[22] Seip RL, Moulin P, Cocke T, Tall AR, Kohrt WM, Mankowitz K, Semenkovich CF, Ostlund R, Schonfeld G. Exercise training decreases plasma cholesteryl ester transfer protein. Arterioscler Thromb 1993;13:1359.

[23] Serrat-Serrat J, Ordonez-Llanos J, Serra-Grima R, Gomez-Gerique JA, Pellicer-Thoma E, Payes-Romero A Gonzalez-Sastre F. Marathon runners presented lower serum cholesteryl ester transfer activity than sedentary subjects. Atherosclerosis 1993;101:43.

[24] McPherson R, Mann CJ, Tall AR, Hogue M, Martin L, Milne RW, Marcel YL. Plasma concentrations of cholesteryl ester transfer protein in hyperlipoproteinemia. Arterioscler Thromb 1991;11:797.

[25] Marotti KR, Castle CK, Boyle TP, Lin AH, Murray RW, Melchior GW. Severe atherosclerosis in transgenic mice expressing simian cholesteryl ester transfer protein. $\mathrm{Na}$ ture 1993;364:73.

[26] Quinet E, Tall AR, Ramakrishnan R, Rudel L. Plasma lipid transfer protein as a determinant of the atherogenicity of monkey plasma lipoproteins. J Clin Invest 1991;87:1559. 